\title{
Oxygen- and glucose-deprived culture promotes cell proliferation and invasion of vascular smooth muscle cells
}

\author{
LIANG $\mathrm{MENG}^{1,2}$ and $\mathrm{BO} \mathrm{YU}^{1}$ \\ ${ }^{1}$ Department of Cardiology, The First Affiliated Hospital of China Medical University, Shenyang 110001;
${ }^{2}$ Department of Circulation, Fengtian Hospital Affiliated to Shenyang Medical College, Shenyang 110024, P.R. China
}

Received May 20, 2011; Accepted June 23, 2011

DOI: $10.3892 / \mathrm{ijmm} .2011 .744$

\begin{abstract}
Excessive proliferation of vascular smooth muscle cells (VSMCs) is an important reason for the formation and development of many vascular remodeling diseases. In pathological conditions, necrosis of VSMCs may result in the release of inflammatory cytokines, which can lead to stimulation of other normal smooth muscle cells, and promote the proliferation of VSMCs. The purpose of this study was to investigate the effect of oxygen- and glucose-deprived (OGD) conditioned medium on VSMC cell proliferation and invasion. Following culture of VSMCs in OGD-conditioned medium, the cell cycle distributions were remarkably altered. The number of cells in the G0/G1 phase decreased, while the number of cells in G2/M and $\mathrm{S}$ phase increased. The expression of cell cycle proteins D1 (Cyclin D1) in VSMCs increased correspondingly. These results suggested that after being cultured in OGD medium, VSMCs can pass through the G0/G1 phase by up-regulation of Cyclin D1 expression, and promote cell proliferation. In addition, we found that the expression of matrix metalloproteinase (MMP)-2 and MMP-9 was increased in OGD medium cultured VSMCs. Using a Transwell invasion assay, we showed that the OGD medium enhanced VSMC cell invasion. These results suggest that MMP-2 and MMP-9 degraded the basement membrane and promoted VSMC invasion. Taken together, our data demonstrate that OGD-conditioned medium can promote VSMC proliferation and invasion by up-regulating Cyclin D1 and MMP-2 and MMP-9 expression, which may contribute to the formation and development of vascular remodeling diseases.
\end{abstract}

\section{Introduction}

Vascular remodeling diseases are characterized by vascular wall thickening and luminal stenosis due to endothelial injury, vascular smooth muscle cell (VSMC) proliferation,

Correspondence to: Dr Bo Yu, Department of Cardiology, The First Affiliated Hospital of China Medical University, 155 North Nanjing Street, Shenyang 110001, P.R. China

E-mail: cmulhyubo@163.com

Key words: vascular smooth muscle cell, oxygen- and glucosedeprived conditioned medium, proliferation, invasion, cell cycle and matrix deposition. Excessive proliferation of VSMCs is an important contributor of the formation and development of many vascular remodeling diseases, such as hypertension, atherosclerosis, restenosis after angioplasty (1-3). Extracellular proliferation and stimulation delivered signal to the nucleus through transmembrane conductance, initiates proliferation related genes, and results in excessive proliferation of VSMCs (4-7). In vascular remodeling diseases especially restenosis after angioplasty, VSMC damage, apoptosis, and necrosis are common pathological processes due to ischemia and hypoxia and their mechanical angioplasty injury (8). In pathological conditions, necrosis of the VSMCs may release inflammatory cytokines that can lead to stimulation of other normal smooth muscle cells, thus promoting the proliferation of VSMC. Cell count, the percentage rate of the cell cycle and cell cycle proteins D1 (Cyclin D1) are important indicators of VSMCs proliferation.

Matrix metalloproteinases (MMPs) are proteolytic enzymes, which can degrade most extracellular matrix components and other substrates (9). MMPs play an important role in cell invasion and metastasis by degrading extracellular matrix, such as collagen type I, laminin, fibronectin and other components. Specifically, MMP-2 and MMP-9, are both type I collagenases and can specifically degrade the main component of the basement membrane, collagen type I, resulting in cell invasion (10).

In this study, we cultured VSMCs in oxygen- and glucosedeprived (OGD) conditioned medium, and investigated the effect of OGD medium on VSMC cell proliferation and invasion as well as the possible underlying mechanisms. We found that OGD-conditioned medium can promote VSMC cell proliferation and invasion, which may be related to subsequent Cyclin D1 and MMPs gene expression.

\section{Materials and methods}

Cell culture. Human aortal VSMCs were obtained from the Chinese Academy of Sciences (Shanghai, China). VSMCs were cultured in low glucose Dulbecco's modified Eagle's medium (DMEM) medium (Gibco) supplemented with $10 \%$ fetal calf serum, $100 \mathrm{U} / \mathrm{ml}$ penicillin, and $100 \mu \mathrm{g} / \mathrm{ml}$ streptomycin at $37^{\circ} \mathrm{C}$ in a humidified atmosphere of $5 \% \mathrm{CO}_{2}$ and $95 \%$ air. The culture medium was changed once every 2-3 days until the cells were grown to $80-90 \%$ confluence for passage. Cells were differentiated for 2 weeks prior to OGD exposure. 
Preparation of OGD-conditioned medium. For OGD, cells were cultured under five different conditions: $10 \%$ serum, low glucose and low oxygen; 5\% serum, low glucose and low oxygen; serum-free, low glucose and low oxygen; serum-free, high glucose and low oxygen; and serum-free, glucose-free and low oxygen. The hypoxic medium was made by gassing with a mixture of $5 \% \mathrm{CO}_{2}, 10 \% \mathrm{H}_{2}$ and $85 \% \mathrm{~N}_{2}$ gas saturation for $15 \mathrm{~min}$. Cells were incubated in a hypoxic medium with high glucose $(25 \mathrm{mM})$, low glucose $(5.5 \mathrm{mM})$, or glucose-free $(0 \mathrm{mM})$ in a closed anaerobic chamber (containing $5 \% \mathrm{CO}_{2}$, $10 \% \mathrm{H}_{2}$ and $85 \% \mathrm{~N}_{2}$ mixture gas). Cells cultured in normal medium under normal conditions served as control.

Trypan blue exclusion assay. Trypan blue is a vital dye excluded only by viable cells with intact cell membranes but not by nonviable cells. After culturing in different conditioned media, cells were collected by gentle trypsinization. A small volume of $0.4 \%$ trypan blue was added to suspended cells, and the number of cells stained with the dye was counted on an inverted optical Olympus microscope using a hemocytometer. A cell was considered positively stained if the entire cytoplasm appeared diffusely blue.

MTT assay. Cell proliferation was measured with the MTT assay. Cells $\left(5 \times 10^{3} / \mathrm{ml}\right)$ were plated in $100 \mu 1$ of medium/well in 96-well plates. After incubation overnight, the cells were cultured with different conditioned medium for varied time. Twenty mililiters of $5 \mathrm{mg} / \mathrm{ml}$ MTT reagent (Sigma) was added to each well containing $180 \mu \mathrm{l}$ of medium, and the plate was incubated for $4 \mathrm{~h}$. After removing the medium, the plates were shaken with dimethylsulfoxide (DMSO) for 5 min to dissolve the formazan crystals. The absorbance of the samples was measured at a wavelength of $490 \mathrm{~nm}$.

Cell cycle analysis. The cell cycle was analyzed by flow cytometry. Briefly, VSMCs were cultured in conditioned medium for 24,48 and $72 \mathrm{~h}$. After incubation, a total of $1 \times 10^{8}$ cells were harvested. The cells were washed twice with PBS and fixed in $75 \%$ ice-cold ethanol overnight. The sample was concentrated by removing the ethanol and staining the cellular DNA with fluorescent solution (1\% (v/v) Triton X-100, 0.01\% RNase, and $0.05 \% \mathrm{PI}$ ) for $30 \mathrm{~min}$ at $4^{\circ} \mathrm{C}$ in darkness. The cell cycle distribution was then detected by a BD FACSCalibur flow cytometry (BD Biosciences, USA). All experiments were performed three times.

$R N A$ isolation and real-time RT-PCR. Total-RNA was isolated from cells using TRIzol reagent (Invitrogen, Carlsbad, CA) according to the manufacturer's instructions. For reverse transcription, $2 \mu \mathrm{g}$ of total-RNA was used to make cDNA in a total of $20 \mu \mathrm{l}$ using the Superscript first strand synthesis kit system according to the manufacturer's protocol (Takara, Dalian, China). Quantitative real-time PCR was carried out in $20 \mu 1$ of reaction mixture containing $10 \mu 1$ of $2 \mathrm{X}$ SYBR-Green Master mix (Takara), $0.5 \mu \mathrm{M}$ of forward and reverse primers, and $5 \mu 1$ template cDNA on a real-time PCR system under the following conditions: $95^{\circ} \mathrm{C}$ for $5 \mathrm{~min}$, followed by 35 cycles of $95^{\circ} \mathrm{C}$ for $10 \mathrm{sec}, 60^{\circ} \mathrm{C}$ for $20 \mathrm{sec}$ and $72^{\circ} \mathrm{C}$ for $30 \mathrm{sec}$. The primer sets used in this study were as follows: Cyclin D1, forward, 5'-CCCGCACGATTTCATTGAAC-3' and reverse,
5'-AGGGCGGATTGGAAATGAAC-3' (134 bp); MMP-2, forward, 5'-TTACACCTACACCAAGAACTTC-3' and reverse, 5'-CAAGGTCAATGTCAGGAGAG-3' (89 bp); MMP-9, forward, 5'-CCTGGAGACCTGAGAACCAATC-3' and reverse, 5'-CCACCCGAGTGTAACCATAGC-3' (79 bp); $\beta$-actin, forward, 5'-CCATCGTCCACCGCAAAT-3' and reverse, 5'-GCTGTCACCTTCACCGTTC-3' (194 bp). The relative target gene expression level was normalized on the basis of $\beta$-actin expression as an endogenous RNA control. All experiments were performed in triplicate.

Western blotting. After culturing in different conditioned media for various time points, whole cells were lysed by sonication in a buffer containing $15 \mathrm{mM}$ Tris- $\mathrm{HCl}(\mathrm{pH} 6.8), 10 \%$ glycerol, $2 \%$ SDS and $6 \% \beta$-mercaptoethanol. The protein concentration was determined by the Bradford method. After incubation at $95^{\circ} \mathrm{C}$ for $10 \mathrm{~min}$, equal volume of protein extracts was separated on $10 \%$ SDS-PAGE gels. The proteins were then transferred to PVDF membranes (Amersham, USA) using a wet-blotting apparatus. Membranes were blocked with $5 \% \mathrm{w} / \mathrm{v}$ non-fat dry milk and $0.1 \% \mathrm{v} / \mathrm{v}$ Tween-20 in PBS, for $1-2 \mathrm{~h}$ at room temperature, and incubated with anti-Cyclin D1 (Cell Signaling Technology, Beverly, MA), anti-MMP2 (Santa Cruz Biotechnology, Santa Cruz, CA), anti-MMP9 (Biosynthesis, Beijing, China), or anti- $\beta$-actin (Boster, Wuhan, China) antibody at $4^{\circ} \mathrm{C}$ overnight. $\beta$-actin was used as endogenous loading control. Signals were visualized with the ECL plus chemiluminiscent reagents (Amersham).

Enzyme-linked immunosorbent assay (ELISA). VSMCs were cultured in an OGD-conditioned medium for $48 \mathrm{~h}$. Media was removed and frozen at $-80^{\circ} \mathrm{C}$. Levels of IL-1, MMP-2 and MMP-9 expression in the OGD medium were determined using the ELISA kits (R\&D Systems, Minneapolis, MN) according to manufacturer's instructions.

Transwell cell invasion assay. The cell invasion assay was performed using 24-well Transwells (Costar) coated with Matrigel (BD BioSciences). Cells (10 $/$ well) were seeded in the upper chambers of the wells in $100 \mu 1$ medium, and the lower chambers were filled with $500 \mu 1$ conditioned medium to induce cell migration. After incubation for 24,48 and $72 \mathrm{~h}$ at $37^{\circ} \mathrm{C}$, and $5 \% \mathrm{CO}_{2}$, the noninvasive cells that remained on the upper surface of the filter were removed by a cotton swab. Cells that traversed through the Matrigel and the polycarbonate filter were attached to the lower surface of the filter, and were fixed with 4\% paraformaldehyde for $15 \mathrm{~min}$, stained with hematoxylin for $5 \mathrm{~min}$, and then examined under a microscope. Cells in at least five random microscopic fields (x200) were counted.

Statistical analysis. Statistical analysis was performed with SPSS 15.0 for Windows (SPSS, Chicago, IL, USA). Quantitative variables were expressed as means $\pm \mathrm{SD}$ and analyzed by the Student's t-test or ANOVA test when appropriate. A P-value $<0.05$ was considered statistically significant.

\section{Results}

Optimization of oxygen-and glucose-deprived culture medium . VSMCs were cultured under different conditioned media and 
Table I. VSMC viability after culture in different conditioned media measured by the trypan blue exclusion assay (mean $\pm \mathrm{SD}$, $n=3)$.

\begin{tabular}{lccc}
\hline & \multicolumn{3}{c}{ Cell number (x10 $/$ well) } \\
\cline { 2 - 4 } Cell culture conditions & $24 \mathrm{~h}$ & $48 \mathrm{~h}$ & $72 \mathrm{~h}$ \\
\hline Control & $4.67 \pm 0.12$ & $5.43 \pm 0.42$ & $6.53 \pm 0.15$ \\
$10 \%$ serum, low glucose, low oxygen & $4.20 \pm 0.26^{\mathrm{a}}$ & $4.00 \pm 0.30^{\mathrm{b}}$ & $3.53 \pm 0.25^{\mathrm{b}}$ \\
$5 \%$ serum, low glucose, low oxygen & $3.93 \pm 0.35^{\mathrm{a}}$ & $3.37 \pm 0.15^{\mathrm{b}}$ & $2.63 \pm 0.38^{\mathrm{b}}$ \\
Serum-free, low glucose, low oxygen & $3.97 \pm 0.32^{\mathrm{a}}$ & $3.33 \pm 0.32^{\mathrm{b}}$ & $2.30 \pm 0.56^{\mathrm{b}}$ \\
Serum-free, high glucose, low oxygen & $3.73 \pm 0.35^{\mathrm{a}}$ & $3.03 \pm 0.42^{\mathrm{b}}$ & $2.47 \pm 0.21^{\mathrm{b}}$ \\
Serum-free, glucose-free, low oxygen & $3.70 \pm 0.44^{\mathrm{a}}$ & $2.70 \pm 0.53^{\mathrm{b}}$ & $2.17 \pm 0.25^{\mathrm{b}}$ \\
\hline
\end{tabular}

${ }^{\mathrm{a}} \mathrm{P}<0.05$ and ${ }^{\mathrm{b}} \mathrm{P}<0.01$ compared to the control group.

Table II. VSMC proliferation after culture in different conditioned media measured by the MTT assay (mean \pm SD, $\mathrm{n}=3$ ).

\begin{tabular}{lccc}
\hline & \multicolumn{3}{c}{ OD value } \\
\cline { 2 - 4 } Cell culture conditions & $24 \mathrm{~h}$ & $48 \mathrm{~h}$ & $72 \mathrm{~h}$ \\
\hline Control & $0.277 \pm 0.01$ & $0.375 \pm 0.03$ & $0.407 \pm 0.03$ \\
10\% serum, low glucose, low oxygen & $0.243 \pm 0.03$ & $0.225 \pm 0.03^{\mathrm{a}}$ & $0.128 \pm 0.03^{\mathrm{a}}$ \\
5\% serum, low glucose, low oxygen & $0.238 \pm 0.03$ & $0.222 \pm 0.02^{\mathrm{a}}$ & $0.121 \pm 0.04^{\mathrm{a}}$ \\
Serum-free, low glucose, low oxygen & $0.235 \pm 0.02$ & $0.196 \pm 0.01^{\mathrm{a}}$ & $0.116 \pm 0.04^{\mathrm{a}}$ \\
Serum-free, high glucose, low oxygen & $0.236 \pm 0.01$ & $0.179 \pm 0.02^{\mathrm{a}}$ & $0.111 \pm 0.01^{\mathrm{a}}$ \\
Serum-free, glucose-free, low oxygen & $0.238 \pm 0.01$ & $0.156 \pm 0.02^{\mathrm{a}}$ & $0.103 \pm 0.02^{\mathrm{a}}$ \\
\hline
\end{tabular}

${ }^{\text {aP }}<0.01$ compared to the control group.

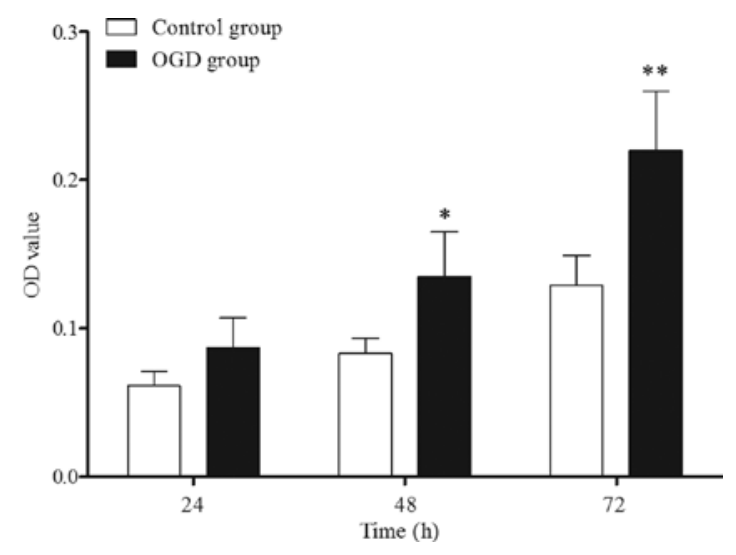

Figure 1. VSMC proliferation in OGD-conditioned medium. VSMCs were cultured in OGD medium for 24, 48 and $72 \mathrm{~h}$. Cell proliferation was determined by the MTT assay. The means and standard deviation (error bar) from three experiments is depicted. ${ }^{\mathrm{P}}<0.05$ compared to the control; ${ }^{* *} \mathrm{P}<0.05$ compared to the previous time point.

the cellular viability was examined using the trypan blue exclusion assay. Compared to the control group, the viabilities of cells cultured in $10 \%$ serum, low glucose and low oxygen medium and 5\% serum, low glucose and low oxygen medium were significantly decreased after $72 \mathrm{~h}$. The viability of the cells cultured in serum-free medium was decreased compared to serum containing medium. Viability of the cells cultured in serum- and glucose-free, low oxygen medium was lowest compared to other groups (Table I). Similarly, the proliferation of cells cultured in low glucose and low oxygen was decreased compared to control group. Cell proliferation was remarkably decreased after culture in serum- and glucose-free, low oxygen medium compared to other groups (Table II). Microscopically, cells cultured in this conditioned medium showed swelling and necrosis. The necrosis was significant after culture for $72 \mathrm{~h}$ (data not shown). The serum- and glucose-free, low oxygen medium cultured with VSMCs for $48 \mathrm{~h}$ was selected as the OGD-conditioned medium and used in subsequent experiments.

Cell proliferation in OGD-conditioned medium cultured VSMCs. VSMCs were cultured in OGD medium for 24, 48 and $72 \mathrm{~h}$, and the proliferation of VSMCs was determined by the MTT assay. After culture in OGD medium, cell proliferation was increased significantly after $48 \mathrm{~h}$ compared to the control groups $(\mathrm{P}<0.05)$ (Fig. 1), suggesting that the optimized OGD condition medium promoted VSMC cell proliferation.

Effects on the cell cycle after VSMC culture in OGD-conditioned medium. VSMCs were cultured in OGD medium for 24,48 

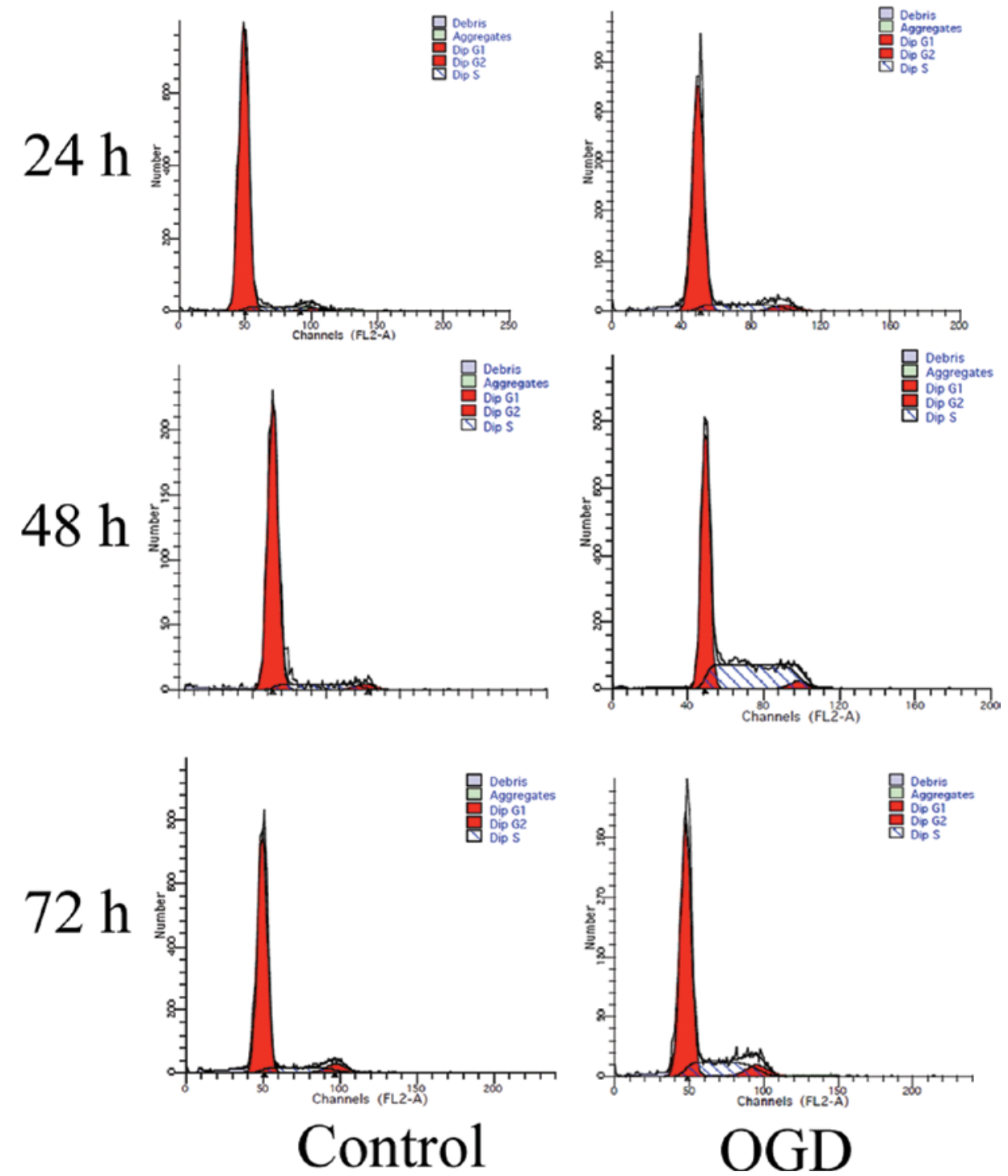

Figure 2. Cell cycle analysis after culture in OGD-conditioned medium. VSMCs were cultured in OGD medium for 24, 48 and $72 \mathrm{~h}$, DNA was stained by propidium iodide and analyzed by flow cytometry. The cell cycle distribution is indicated.

Table III. Cell cycle distribution of VSMCs after culture in OGD and control media (mean $\pm \mathrm{SD}, \mathrm{n}=3$ ).

\begin{tabular}{cccc}
\hline Group & G0/G1 & G2/M & S \\
\hline Control & & & $7.03 \pm 1.25$ \\
$24 \mathrm{~h}$ & $90.37 \pm 1.42$ & $2.60 \pm 0.32$ & $10.92 \pm 0.94$ \\
$48 \mathrm{~h}$ & $86.20 \pm 1.22$ & $2.88 \pm 0.32$ & $11.07 \pm 0.41$ \\
$72 \mathrm{~h}$ & $83.06 \pm 0.63$ & $5.87 \pm 0.84$ & \\
OGD & & & $10.51 \pm 1.00$ \\
$24 \mathrm{~h}$ & $85.59 \pm 0.60^{\mathrm{a}}$ & $3.91 \pm 1.13$ & $6.07 \pm 0.98^{\mathrm{a}, \mathrm{b}}$ \\
$48 \mathrm{~h}$ & $75.20 \pm 0.69^{\mathrm{a}}$ & $18.73 \pm 0.47^{\mathrm{a}}$ & $6.07 \pm 0.98^{\mathrm{a}, \mathrm{b}}$ \\
$72 \mathrm{~h}$ & $71.64 \pm 0.61^{\mathrm{a}}$ & $18.73 \pm 0.47^{\mathrm{a}}$ &
\end{tabular}

${ }^{\mathrm{a}} \mathrm{P}<0.05$ compared to the control group; ${ }^{\mathrm{b}} \mathrm{P}<0.05$ compared to the previous time point.

and $72 \mathrm{~h}$, and subjected to flow cytometry analysis. After culturing in OGD medium, the number of cells in the G0/G1 phase decreased and that in the G2/M and S phase increased, suggesting that VSMCs cultured in OGD medium transitioned 
A
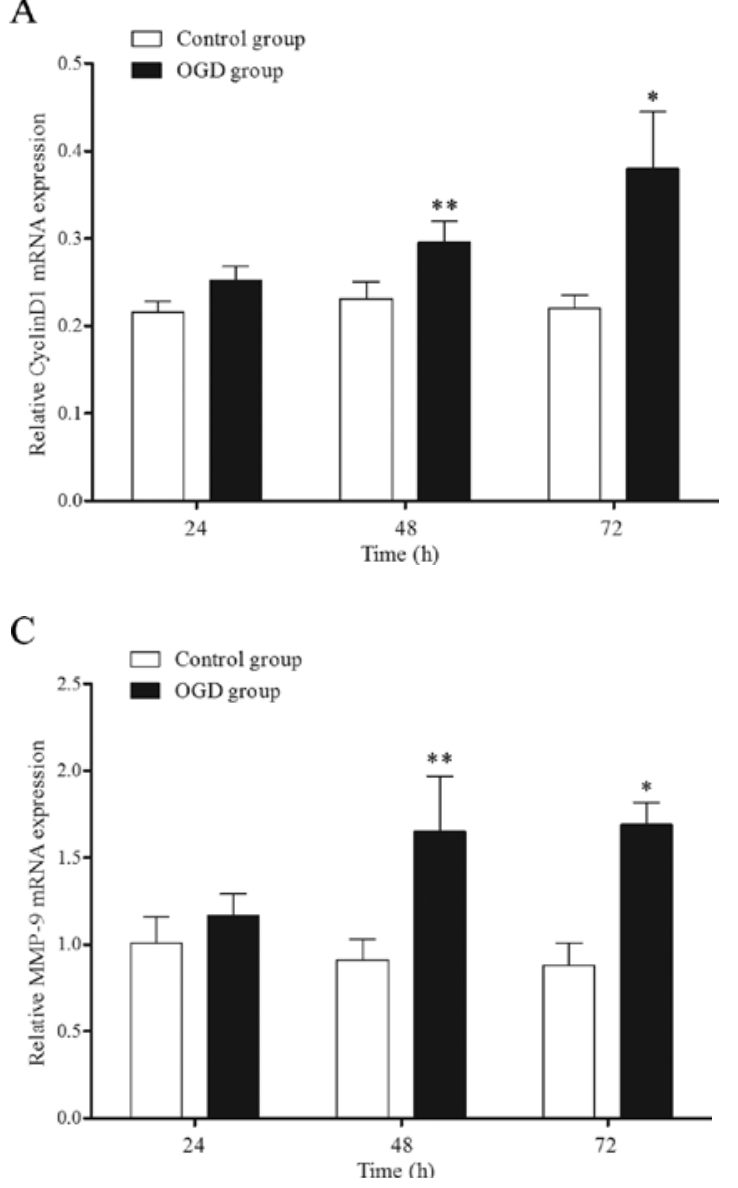

B

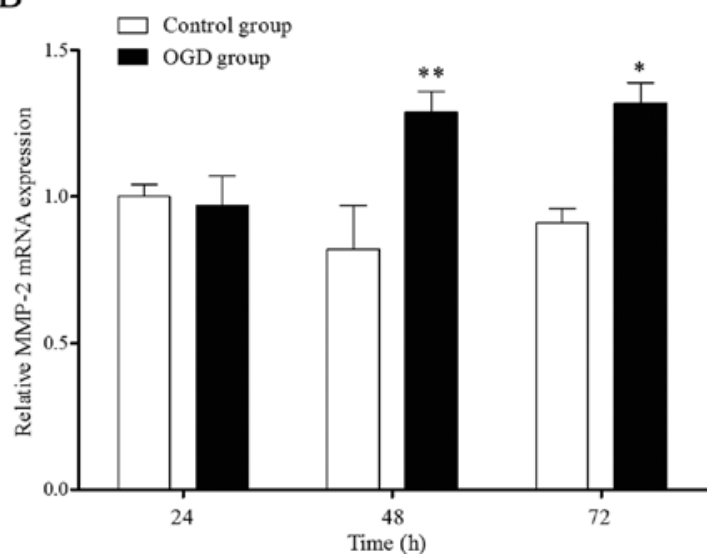

D

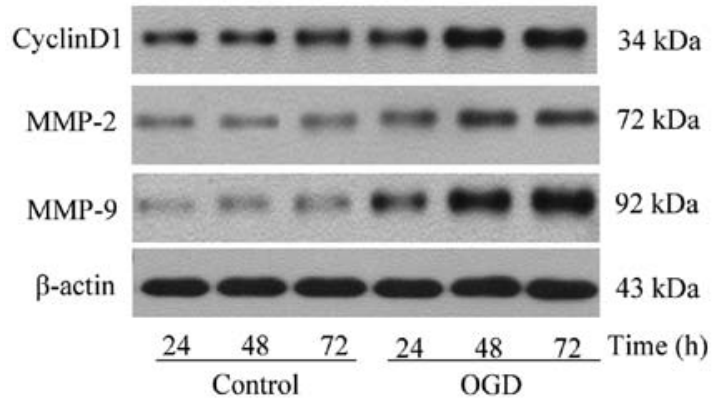

Figure 3. Cyclin D1, MMP-2 and MMP-9 expression in OGD medium cultured VSMCs. VSMCs were cultured in OGD medium for 24, 48 and $72 \mathrm{~h}$. (A) Cyclin D1, (B) MMP-2 and (C) MMP-9 mRNA levels were determined by quantitative RT-PCR. When measured at the 24-h time point, Cyclin D1 mRNA levels were significantly increased after culture in the OGD medium compared to the unexposed cells. There were no obvious differences in the mRNA levels of MMP-2 and MMP-9 mRNA $24 \mathrm{~h}$ after culture in OGD medium compared with the control group, however, a significant increase was detected at 48 and $72 \mathrm{~h}$. The means (symbol) and standard deviation (error bar) from three experiments is depicted. ${ }^{*} \mathrm{P}<0.05$ compared to the control; ${ }^{* *} \mathrm{P}<0.05$ compared to the previous time point. (D) Western blot analysis showed the same pattern of change in Cyclin D1, MMP-2 and MMP-9 protein levels after culture in OGD medium. Equivalence of loading of cell lysates is shown by the anti- $\beta$-actin labeling.

from the G1 phase to the $\mathrm{S}$ and $\mathrm{G} 2 / \mathrm{M}$ phases of the cell cycle (Fig. 2). Quantitative analysis showed that cells in the $\mathrm{S}$ phase of the cell cycle decreased slightly and those in the $\mathrm{G} 2 / \mathrm{M}$ phase increased significantly $(\mathrm{P}<0.05)($ Table III).

Cyclin D1, MMP-2 and MMP-9 expression in OGD medium cultured VSMCs. Cyclin D1, MMP-2 and MMP-9 mRNA levels were determined by quantitative RT-PCR. When measured $24 \mathrm{~h}$ after culturing in the OGD medium, Cyclin D1 mRNA levels were significantly increased in VSMCs cultured in OGD medium compared to the unexposed control cells. There were no obvious differences in the mRNA levels of MMP-2 and MMP-9 mRNA at $24 \mathrm{~h}$ compared with the control group; however, significant increases were detected at 48 and $72 \mathrm{~h}$ after culturing in OGD medium (Fig. 3A-C). The same pattern of change in Cyclin D1, MMP-2 and MMP-9 protein levels was observed after culturing in OGD medium. After culturing in OGD medium, Cyclin D1, MMP-2 and MMP-9 proteins were significantly increased compared to the control groups (Fig. 3D).

IL-1, MMP-2 and MMP-2 levels in OGD-conditioned media. The IL-1, MMP-2 and MMP-9 levels in OGD-conditioned media were measured by ELISA. The IL-1 levels in the OGD medium was $32.54 \pm 0.80 \mu \mathrm{g} / \mathrm{ml}$ and significantly higher than that in control normal medium, $0.178 \pm 0.002 \mu \mathrm{g} / \mathrm{ml}(\mathrm{P}<0.01)$. After culturing of VSMCs in OGD-conditioned medium, MMP-2 and MMP-9 levels were slightly increased compared to that in the control normal medium. However, at 48 and $72 \mathrm{~h}$ after culture in OGD medium, the MMP-2 and MMP-9 levels were significantly higher than those in the control medium (Fig. 4).

Effect of IL-1 on VSMC proliferation. To determine whether IL-1 can promote VSMC proliferation, cells were cultured in normal control medium, normal control medium with IL-1, OGD-conditioned medium, and OGD-conditioned medium with IL-1. As shown in Fig. 5, compared to the control group, both IL-1 and the OGD medium promoted cell proliferation. However, when VSMCs were cultured in OGD medium with IL-1 RA, an IL-1 antagonist, cell proliferation was decreased. These findings demonstrated that IL-1 in the OGD medium can promote VSMC proliferation.

Effect of OGD medium on VSMC invasion. VSMCs were cultured in OGD-conditioned medium and serum-free control 
A

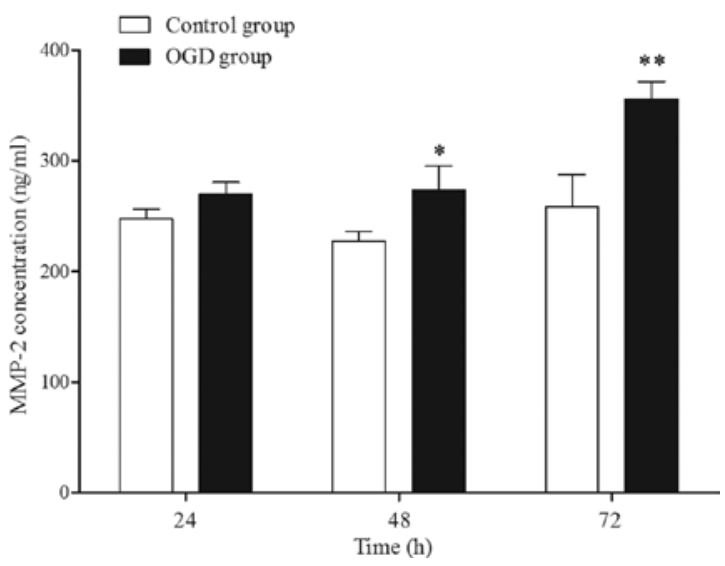

B

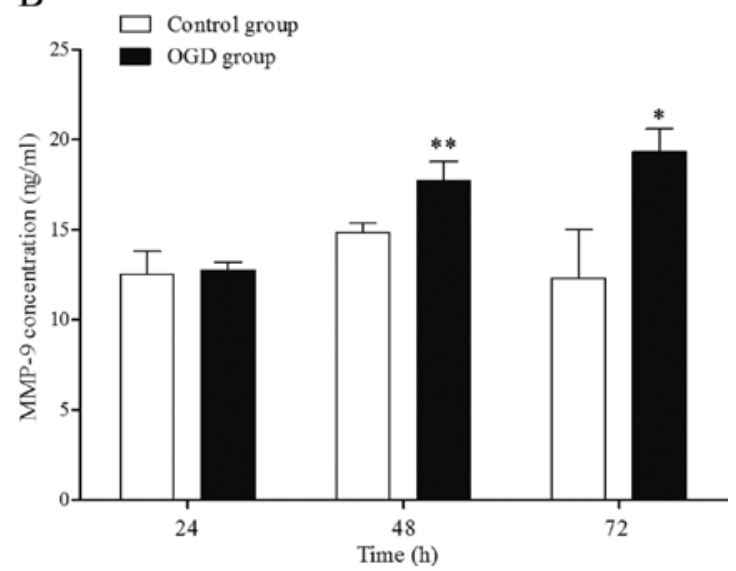

Figure 4. MMP-2 and MMP-9 levels in OGD-conditioned medium. The MMP-2 and MMP-9 levels in the medium were measured by ELISA. After culturing VSMCs in OGD-conditioned medium for 48 and $72 \mathrm{~h}$, (A) MMP-2 and (B) MMP-9 levels were significantly increased in the OGD medium compared to that in the control normal medium. The means and standard deviation (error bar) from three experiments is depicted. $\mathrm{P}<0.05$ compared to the control; ${ }^{* *} \mathrm{P}<0.05$ compared to the previous time point.

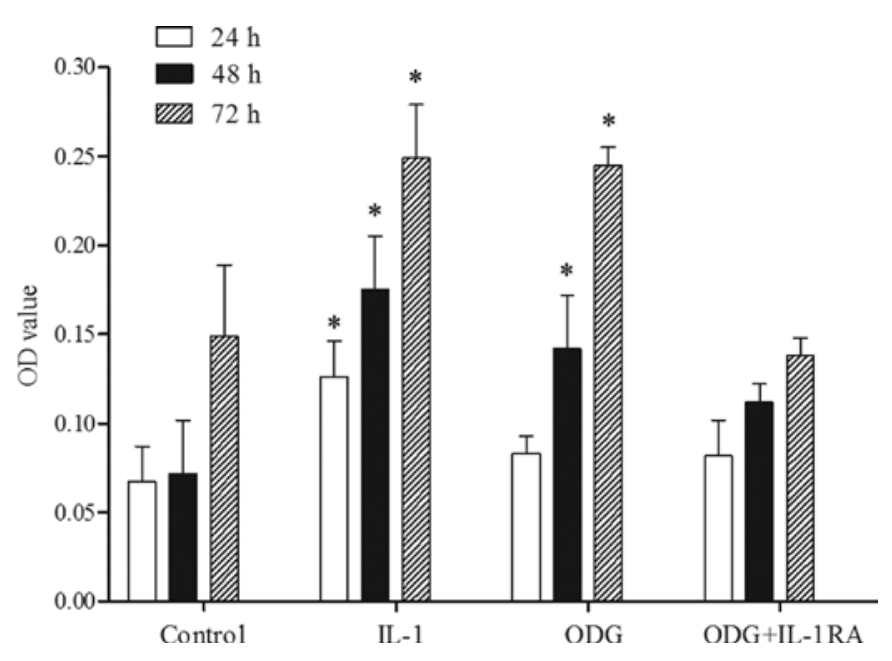

Figure 5. Effect of IL-1 on VSMC cell proliferation. Cells were cultured in normal control medium, normal control medium with IL-1, OGD-conditioned medium, and OGD medium with IL-1 for 24, 48 and $72 \mathrm{~h}$. Compared to the control group, both IL-1 and the OGD medium promoted cell proliferation. VSMCs cultured in OGD medium with IL-1 RA, an IL-1 antagonist, showed decreased cell proliferation. The means and standard deviation (error bar) from three experiments is depicted. ${ }^{*} \mathrm{P}<0.05$ compared to control.

medium for up to $72 \mathrm{~h}$ and subjected to a Transwell assay. After culturing for $24 \mathrm{~h}$, the invasion of VSMCs cultured in OGD medium was slightly higher than that of cells cultured in the control medium. However, after 48 and $72 \mathrm{~h}$ of incubation, VSMCs cultured in OGD medium exhibited significantly enhanced invasion as compared to that of cells cultured in control medium (Fig. 6). These findings suggest that the OGD-conditioned medium promoted VSMC cell invasion.

\section{Discussion}

Cardiovascular diseases are diseases that involve the heart or blood vessels and are the most common causes of death worldwide. VSMC proliferation is an important pathological basis of these diseases. VSMCs are differentiated from embryonic

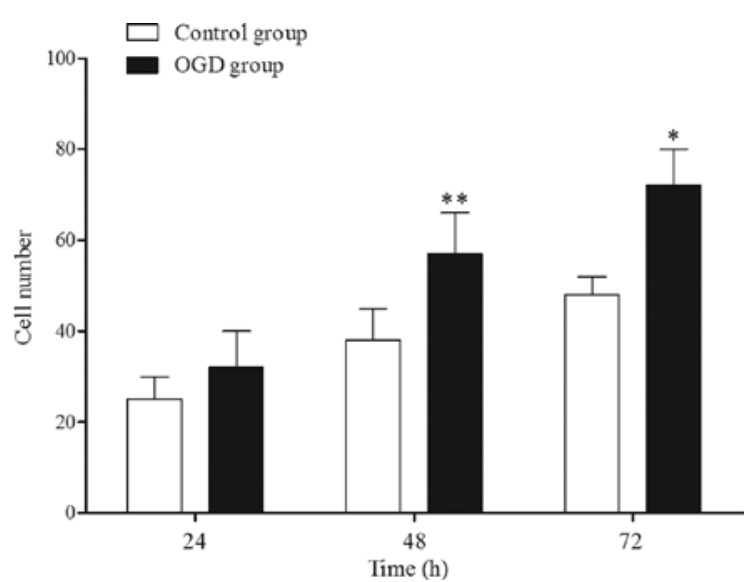

Figure 6. Effect of OGD medium on VSMC cell migration. VSMCs were cultured in OGD-conditioned medium and serum-free control medium for up to $72 \mathrm{~h}$ and subjected to a Transwell assay. After culture for $24 \mathrm{~h}$, the invasion of VSMCs cultured in OGD medium was slightly higher than of those cultured in control medium. However, after 48 and $72 \mathrm{~h}$ of incubation, OGD medium cultured VSMCs exhibited significant enhancement of cell invasion as compared to that cultured in control medium. Data are the means \pm SD of results in triplicate experiments. ${ }^{*} \mathrm{P}<0.05$ compared to control; ${ }^{* *} \mathrm{P}<0.05$ compared to the previous time point.

mesenchyme, and possess the functions of contraction, and synthesis and secretion of extracellular matrix. The structure and function of VSMCs may change significantly at different developmental stages and under different physiological or pathological states (11-14). Recent studies have found that various growth factors, vasoactive substances, and cytokines released from damaged endothelial vessel wall can activate VSMC surface receptors and signal transduction, which result in VSMC cell proliferation and invasion (15-18).

VSMC necrosis is a common phenomenon in vascular remodeling. Necrotic VSMCs may release inflammatory factors such as IL-1. IL-1 can induce NF- $\kappa$ B inhibitor I $\kappa$ B kinases $\alpha$ and $\mathrm{I} \kappa \mathrm{B}$ kinases $\beta$, which cause the proliferation of human VSMC cell proliferation (19). In addition, a previous study has found that IL-1 $\alpha$ receptor antagonists can inhibit the proliferation of VSMCs, suggesting that an IL-1 $\alpha$ receptor antagonist 
can interfere with the IL-1 autocrine pathway in VSMCs by antagonizing the role of IL-1 $\alpha$ (20). In this study, we showed that IL-1 expression was increased in OGD-conditioned medium, and IL-1 could promote VSMC proliferation. After adding IL-1 antagonist, VSMC cell proliferation was decreased. These findings demonstrated that VSMC cell proliferation was induced by IL-1 in the OGD-conditioned medium.

Cyclin D1 is a cell cycle regulator, and plays an important role in G1-S progression (21). In this study, after culturing of VSMCs in OGD-conditioned medium, the cell cycle distributions were remarkably changed. G0/G1 phase cells decreased, and G2/M and $\mathrm{S}$ phase cells increased. The expression of Cyclin D1 in VSMCs was increased correspondingly. These results suggest that after culturing in OGD-conditioned medium, VSMCs can pass through the G0/G1 phase by up-regulation of Cyclin D1 expression, and promote cell proliferation.

Previously, MMP-2 and MMP-9 have been showed to promote the migration of VSMCs by degradation of the basement membrane (22,23). Miyajima et al (24) found that in rabbit corneal fibroblasts and human fibrosarcoma cells, IL- $\beta$ and cell necrosis factor (TNF)- $\alpha$ can increase MMP-9 expression. These inflammatory factors have also been found to increase MMP-9 expression in primary cultured human corneal epithelial cells (25). In our study, we found that the expression of MMP-2 and MMP-9 were increased in VSMCs that were cultured in OGD medium. The Transwell invasion assay showed that VSMCs cultured in OGD-conditioned medium enhanced cell invasion compared with the control cells, which is consistent with the increased expression of MMP-2 and MMP-9, suggesting that MMP-2 and MMP-2 degraded the basement membrane and promoted VSMC cell invasion.

In conclusion, we successfully established the VSMC OGD-conditioned model. In the OGD-conditioned medium, IL-1 was increased and induced VSMC cell proliferation. We also demonstrated that the OGD medium can promote VSMC proliferation by up-regulation of Cyclin D1 expression, and induction of cell cycle progression. In addition, we provide evidence indicating the enhancement of OGD medium cultured VSMC cell invasion by increased MMP-2 and MMP-9 expression and secretion.

\section{References}

1. Lusis AJ: Atherosclerosis. Nature 407: 233-241, 2000.

2. Libby $\mathrm{P}$ and Tanaka H: The molecular bases of restenosis. Prog Cardiovasc Dis 40: 97-106, 1997.

3. Clowes AW, Clowes MM, Fingerle J and Reidy MA: Regulation of smooth muscle cell growth in injured artery. J Cardiovasc Pharmacol 14 (Suppl 6): S12-S15, 1989.

4. Brassard P, Amiri F and Schiffrin EL: Combined angiotensin II type 1 and type 2 receptor blockade on vascular remodeling and matrix metalloproteinases in resistance arteries. Hypertension 46: 598-606, 2005.

5. YaghiniFA,Song CY,LavrentyevEN,etal:AngiotensinII-induced vascular smooth muscle cell migration and growth are mediated by cytochrome P450 1B1-dependent superoxide generation. Hypertension 55: 1461-1467, 2010.
6. Berk BC: Vascular smooth muscle growth: autocrine growth mechanisms. Physiol Rev 81: 999-1030, 2001.

7. Geng YJ and Libby P: Progression of atheroma: a struggle between death and procreation. Arterioscler Thromb Vasc Biol 22: 1370-1380, 2002.

8. Kavurma MM, Bhindi R, Lowe HC, Chesterman C and Khachigian LM: Vessel wall apoptosis and atherosclerotic plaque instability. J Thromb Haemost 3: 465-472, 2005.

9. Swarnakar S, Paul S, Singh LP and Reiter RJ: Matrix metalloproteinases in health and disease: regulation by melatonin. J Pineal Res 50: 8-20, 2011.

10. Lu KV, Jong KA, Rajasekaran AK, Cloughesy TF and Mischel PS: Up-regulation of tissue inhibitor of metalloproteinases (TIMP)-2 promotes matrix metalloproteinase (MMP)-2 activation and cell invasion in a human glioblastoma cell line. Lab Invest 84: 8-20, 2004.

11. Blanc A, Pandey NR and Srivastava AK: Synchronous activation of ERK 1/2, p38mapk and PKB/Akt signaling by $\mathrm{H}_{2} \mathrm{O}_{2}$ in vascular smooth muscle cells: Potential involvement in vascular disease (Review). Int J Mol Med 11: 229-234, 2003.

12. Paik JH: FOXOs in the maintenance of vascular homoeostasis Biochem Soc Trans 34: 731-734, 2006.

13. Allard D, Figg N, Bennett MR and Littlewood TD: Akt regulates the survival of vascular smooth muscle cells via inhibition of FoxO3a and GSK3. J Biol Chem 283: 19739-19747, 2008.

14. Meng D, Lv DD and Fang J: Insulin-like growth factor-I induces reactive oxygen species production and cell migration through Nox4 and Rac1 in vascular smooth muscle cells. Cardiovasc Res 80: 299-308, 2008.

15. Skaletz-Rorowski A, Waltenberger J, Muller JG, Pawlus E, Pinkernell $\mathrm{K}$ and Breithardt $\mathrm{G}$ : Protein kinase $\mathrm{C}$ mediates basic fibroblast growth factor-induced proliferation through mitogenactivated protein kinase in coronary smooth muscle cells. Arterioscler Thromb Vasc Biol 19: 1608-1614, 1999.

16. Pasche B: Role of transforming growth factor beta in cancer. $\mathrm{J}$ Cell Physiol 186: 153-168, 2001.

17. Papapetropoulos A, Rudic RD and Sessa WC: Molecular control of nitric oxide synthases in the cardiovascular system. Cardiovasc Res 43: 509-520, 1999.

18. Anea CB, Ali MI, Osmond JM, et al: Matrix metalloproteinase 2 and 9 dysfunction underlie vascular stiffness in circadian clock mutant mice. Arterioscler Thromb Vasc Biol 30: 2535-2543, 2010.

19. Sasu S and Beasley D: Essential roles of IkappaB kinases alpha and beta in serum- and IL-1-induced human VSMC proliferation. Am J Physiol Heart Circ Physiol 278: H1823-H1831, 2000.

20. Schultz K, Murthy V, Tatro JB and Beasley D: Endogenous interleukin-1 alpha promotes a proliferative and proinflammatory phenotype in human vascular smooth muscle cells. Am J Physiol Heart Circ Physiol 292: H2927-H2934, 2007.

21. Ferrer JL, Dupuy J, Borel F, Jacquamet L, Noel JP and Dulic V: Structural basis for the modulation of CDK-dependent/independent activity of cyclin D1. Cell Cycle 5: 2760-2768, 2006.

22. Newby AC: Dual role of matrix metalloproteinases (matrixins) in intimal thickening and atherosclerotic plaque rupture. Physiol Rev 85: 1-31, 2005.

23. Garanich JS, Pahakis M and Tarbell JM: Shear stress inhibits smooth muscle cell migration via nitric oxide-mediated downregulation of matrix metalloproteinase-2 activity. Am J Physiol Heart Circ Physiol 288: H2244-H2252, 2005.

24. Miyajima S, Akaike T, Matsumoto K, et al: Matrix metalloproteinases induction by pseudomonal virulence factors and inflammatory cytokines in vitro. Microb Pathog 31: 271-281, 2001.

25. Li DQ, Lokeshwar BL, Solomon A, Monroy D, Ji Z and Pflugfelder SC: Regulation of MMP-9 production by human corneal epithelial cells. Exp Eye Res 73: 449-459, 2001. 